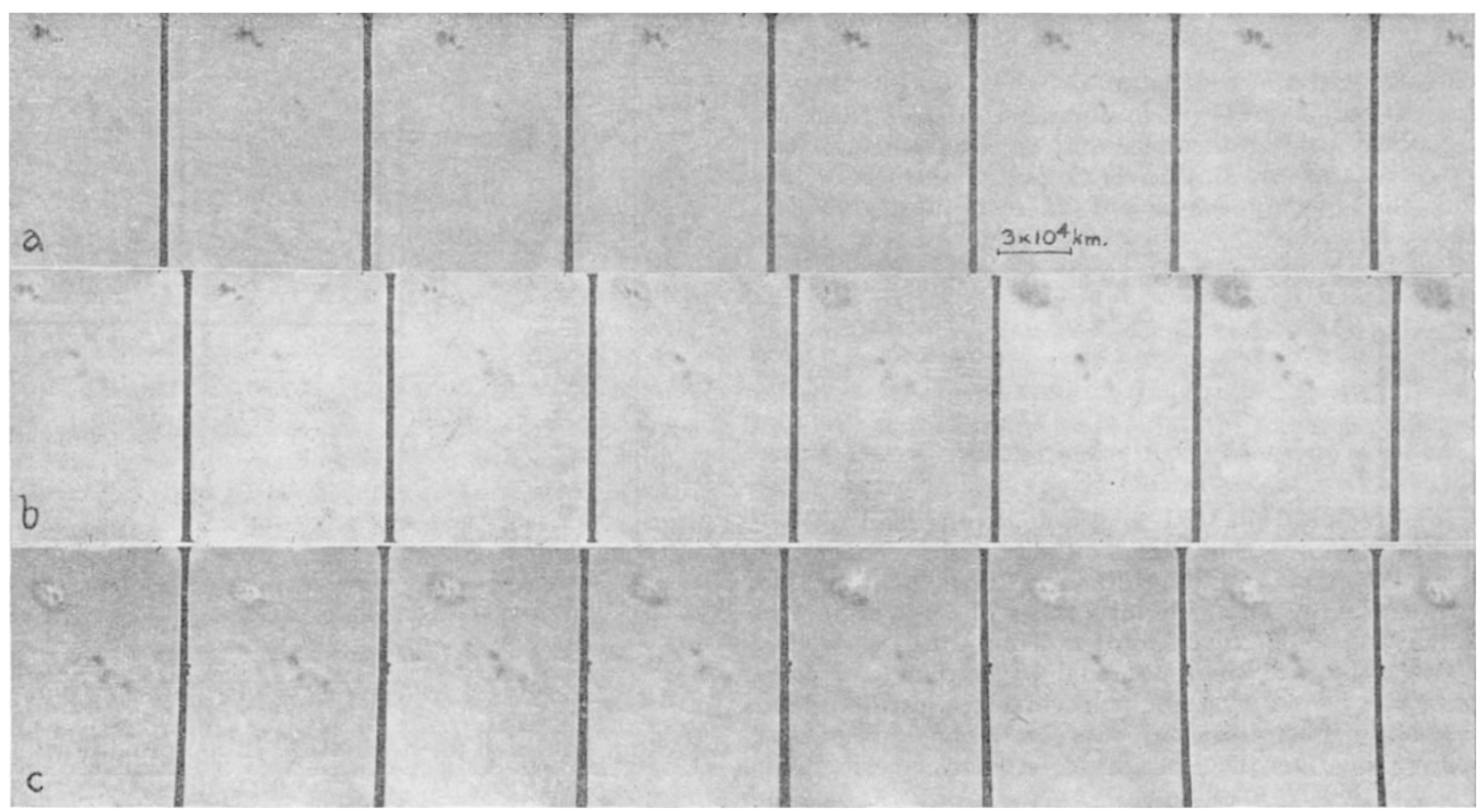

an abnormally bright region surrounding the umbra which is soon obscured or obliterated by the rapidly forming penumbra. Strip (c) was exposed about one minute after $(b)$. Here the brightening next to the umbra is very much enhanced and appears to be almost the size of the penumbra, which is still well developed. The brightened area appears to be in violent motion. The speed shown by the 'flare' in frame 5 of $(c)$ is of the order of $50,000 \mathrm{~km}$. per sec., which would seem to prove that this is due to excitation rather than motion of material.

I have been unable to obtain solar noise records for 2,700-3,000 Mc./s. for the time during which the photographs were made. Some $H_{a}$ flare activity was noted in this region during this time, but, to my knowledge, none occurred while the pictures were being taken.

This work was supported, in part, by the U.S. Army Signal Corps, under Contract No. DA36-039$8 c-64524$.

RCA Solar Observatory, Rocky Point,

New York. Nov. 1.

'Nature, 168, 291 (1951).

\section{Germanium in Power Station Boiler Plant}

CRAWLEY ${ }^{1}$ has reported the results of a search for germanium in the waste products of the major coalburning industries of Britain. We have determined the quantity of germanium in more than sixty samples of dust and deposits taken from various types of steam-raising plant within the British Electricity Authority ; the results have not been encouraging.

In boilers fired with pulverized fuel, nearly all the ash from the fuel is carried forward with the flue gases, and it is therefore unlikely that appreciable enrichment of germanium will occur in the fly-ash. Analysis of several samples of fly-ash confirmed that the germanium content was very low, and even ash which had remained in the plant for some time, for example at the base of the chimney, was found to contain only 0.01 per cent. When the fuel is burned in a stoker-fired furnace, however, only a few per cent of the total ash in the fuel is carried forward and some enrichment due to condensation or ad. sorption on the fly-ash might be expected. Tho maximum concentration found in such ashes was only 0.015 per cent.

Selective condensation of inorganic constituents of the coal causes deposits to be formed in varying quantities throughout the boiler. It has been found that many of these deposits contain more germanium than the coals from which they were derived; but in only two, both from the superheater, was the germanium content greater than 0.1 per cent, which is the minimum concentration likely to repay recovery. The maximum concentration found was $0 \cdot 16$ per cent. Amounts between 0.05 and 0.1 per cent were found in ten out of forty samples of deposit taken from various parts of the system, including the induced-draught fans. The remainder of the deposits contained $0.003-0.05$ per cent. It appears from these figures that deposits from steam-raising plant only occasionally contain useful amounts of germanium. Even then, the quantities of these deposits available are usually small ; at most, about a ton could be recovered with some difficulty from one boiler in a year.

If the conditions of combustion and the constituents in the coal which affect the release of germanium could be determined, it might be possible to forecast which boilers were likely to have deposits rich in germanium. Experiments are therefore being made to see whether pyrites and the chlorides of sodium and potassium affect the release of germanium during the combustion of coal.

Research Laboratories,

\section{J. S. Forrest \\ A. C. Sмrtrh}

J. M. WARD

British Electricity Authority,

Randall's Farm Lane,

Leatherhead.

$$
\text { Feb. } 25 .
$$

${ }^{2}$ Crawley, R. H. A., Nature, 175, 291 (1955). 